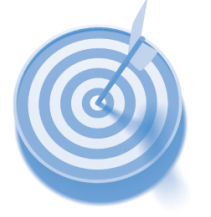

Charlotte Thorley
Department of Physical
Sciences
South East Physics
Network
Queen Mary
University of London
Mile End Road
London
E3 2EB

charlotte.thorley

@sepnet.ac.uk

\section{SEPnet Outreach: building and sustaining links between university physics departments}

\begin{abstract}
The SEPnet Outreach work strand is a collaboration between university physics departments around the South East of England as a direct response to the national STEM agenda and the recruitment needs of the partner departments. A portfolio of activities has been developed that builds on the strengths of each department to deliver higher impact through collaborative development and delivery. In particular, the two year repeat contact 'SEPnet GCSE Programme' shows that a region-wide programme drawing inspiration not just from the physics departments but the school teachers they work with can be particularly effective. This paper looks at the successes of the activities so far, and takes a look ahead.

\section{Introduction}

In 2008 HEFCE awarded £12.5 million to a consortium of physics departments in the South East of England to support and sustain physics as a subject. Prompted by the closure of many physical sciences departments in 2006 the fledgling consortium tasked Nigel Brown and Associates to produce a review of the state of university physics in the South East ${ }^{1}$. This review highlighted various vulnerabilities, a message reinforced when the physics department at the University of Reading closed. As a response the group worked with HEFCE to gain financial support from the SIVS ${ }^{2}$ (strategically important and vulnerable subjects) programme. This grant was awarded to the consortium to support physics on multiple levels increasing sustainability in the departments. By this time the consortium had settled to include six universities: the University of Kent; Royal Holloway, University of London; Queen Mary, University of London; University of Southampton; University of Surrey; and University of Sussex. The University of Portsmouth and Oxford University both held Associate partner positions due to their participation in the SEPnet-Astro research theme until mid 2010 when Portsmouth launched their new undergraduate physics degree and became a full partner. Oxford continues to have strong links not just to SEPnet-Astro but to the Outreach strand as well.
\end{abstract}

A significant factor highlighted by the Brown report, reflecting national STEM (science, technology, engineering and mathematics) policy thinking ${ }^{3,4,5,6,7}$ at the time, was the shortage in applications to undergraduate physics degrees, and consequently a low undergraduate population. Recommendations included the formulation of a regional structure to support the existing outreach provision, and production of a knowledge base for the partners building on and complementing existing AimHigher frameworks and Institute of Physics (IOP) initiatives. The resulting SEPnet Outreach work strand forms a significant part of the SEPnet project. Each partner site has a designated delivery budget and Outreach officer for physics to enable regional delivery of outreach activities from the departments. To ensure that delivery is region-wide and to enable practice transfer between sites there is also a Director of Outreach for the consortium, facilitating strong links to the IOP, HE STEM programme and other STEM agenda initiatives.

This paper will provide an overview of the SEPnet Outreach strand, looking at the impact this has had on the departments and local schools to date, and the plans to sustain the activity beyond the end of the funding period.

\section{SEPnet Outreach}

Whilst acknowledging a need to drive up undergraduate numbers, the SEPnet Outreach strand was tasked to look beyond recruitment, using Outreach as a catch-all term for enhancement and enrichment activities, inspirational activities and wider public engagement. Time limited by the HEFCE grant which ends in 2013, the key audiences for interactions were identified as those at key stages four and five, studying for their GCSEs and A-levels. The perception was that any outreach activity carried out on a regional level would contribute towards the number of students interested in and qualified to take up a degree in physics, but would not be able to be tracked directly to 
recruitment numbers in the individual departments. It was however noted that anecdotally departments with active outreach programmes appear to recruit better than those that do not, and where the driver for such a programme (e.g. Outreach Officer) is removed a subsequent drop in undergraduate application can often be seen.

There were many logistical issues in getting SEPnet off the ground, including delays with recruitment of the central staff. Outreach was one area all partners could agree needed to be addressed quickly if it were to have a tangible effect, and so the flagship SEPnet GCSE Programme was used as a tool to bring the partners together. Other initiatives followed, and the GCSE Programme itself has been re-envisioned now that all the staff are in place, but in the beginning it served as a good testing ground for working together and forcing the departments to think beyond their own specialties and needs.

\section{Collaboration}

Imposing a network on the departments involved does not mean that they will find it easy to work together. Finance can be an effective lever in getting people to say they will engage, and even to take actions that look like they are doing so. The real collaboration can only start when the people on the ground, developing and delivering activities, are enabled to share practice and ideas and feel rewarded for doing so.

To this end a culture shift has been necessary in many of the partners. All of the departments in the network carried out outreach of some kind prior to SEPnet, such as lectures to schools or interest groups, hosting campus visits and student placements, or engaging with national schemes such as STEM ambassadors. So there was no doubt that the will to share knowledge of and passion for physics was there. What was missing in most cases was a rationale behind the interaction, other than thinking it might be a good idea.

The introduction of SEPnet Outreach provided a chance to pause and rethink what activities were on offer, and why. Regular meetings and discourse between staff both within their departments, and across the network has been invaluable in highlighting effective practice, and showing where efforts were being duplicated or even wasted.

Our structure includes:

- Regular officers group meetings for the dedicated SEPnet staff, often involving training

- Regional steering group meetings, for the Officers and other interested partners to guide the programmes

- Teacher Advisory group meetings, where teachers representing the range of schools we work with have a chance to tell us what they and their students need

- Use of the SEPnet governance to engage with Senior management in the partner universities

Getting this structure right has taken time, and it continues to evolve to meet the changing conditions in HE and schools. SEPnet is in a position now that includes a good mix of knowledgeable professionals to drive outreach activity in the departments, but that also has the buy-in of departmental staff and local schools. Activities that already existed have been guided to the best audiences, reinvigorated and renewed by idea sharing and in some cases have been stopped. New activities are designed to build on the strengths and research specialties of the individual departments, but also those of the network, and are always targeted for their audience. Undergraduate and post-graduate students are keen to engage. Increasing numbers are trained to help with delivery of activities, becoming strong communicators and great ambassadors for physics.

Underpinning all of this are the joint projects that are delivered regionally by all the departments, developed together, guided by audience need and providing high visibility through scale of delivery. The GCSE Programme provides a bank of activities for the partners that are curriculum relevant but draw out research highlights. Activities can be added or removed as necessary, but the underlying structure provides regular contact for schools, building up their relationship with the universities, and opening up other opportunities.

\section{The GCSE Programme}

- What is Physics? Taster session: a half-day on-campus activity that includes lectures and a carousel of large hands-on experiments, currently themed around Energy

- In-class activities: sessions designed to fit into a single lesson, covering curriculum topics. Includes Rollercoaster Physics, Radical Radioactivity, A walk through the EM Spectrum

- How to Ace your a-Levels: a full-day on-campus activity introducing core A-level physics topics and the maths that supports it all.

Importantly for SEPnet, this programme represents the results of ongoing teacher consultation. Previously there had been a lack of knowledge in the departments about changes to the curriculum and teaching in schools, and consequently a lot of guesswork being used, which has now been mitigated. Each in-class session can be delivered by the universities, but the teachers are encouraged to spend time with the equipment, and even to borrow it for their own classes. In this way we are providing a professional development opportunity without pressure, particularly useful for non-specialist teachers.

\section{Results}

Each department within the network has its own strengths and research specialties. Naturally these are represented in the portfolio of outreach activities on offer. The majority of the outreach work carried out by the departments before SEPnet was introduced fell into the 'inspirational' category, but now would qualify as enhancement and enrichment. The main collaborative projects have elements of both within them, and make best use of the dedicated Outreach staff in introducing schools education terms and processes to the departmental staff and students. All activities are developed in an environment of shared knowledge and resources, but some projects show this more than others. Particularly strong joint projects include $\mathrm{LightTAG}^{8}$, an arts and science project for NEETS that resulted in a travelling exhibition currently touring the region, the SEPnet Physics Olympics, which will see groups of A-level students competing in physics challenges based on Olympic sports. 
Response so far has been overwhelmingly positive. The GCSE Programme saw 55 schools attend the introduction sessions on campus in 2010 , whilst over 300 schools engaged with the wider programmes. Workshop sessions are well received in school, and are being used outside of the project for training student outreach ambassadors and delivery as standalone activities. Teachers are using contact through promotion of this scheme to allow them to engage with the departments in different ways, often leading to lectures or open day visits, whilst at the same time the teacher advisory group is being used as a resource for the development of other outreach activities both regionally and locally.

\section{Knowledge of schools and the issues in science teaching is seeping into departmental staff, and with it has come acknowledgment of the importance of having a dedicated member of outreach staff with professional skills.}

It will take time to see the full impact of the programme on the school students and teachers, and may be impossible to link this activity causally to undergraduate recruitment, but the consequences can already be seen in the departments. A shift has occurred in the perception of the role of the outreach officer. Knowledge of schools and the issues in science teaching is seeping into departmental staff, and with it has come acknowledgment of the importance of having a dedicated member of outreach staff with professional skills. The departments have in the last month signed up to continue SEPnet Outreach indefinitely beyond the HEFCE funding period, acknowledging the value of the departmental and central staffing positions, and each contributing to the funds needed for these roles. The HEFCE funding has provided great start-up security, allowing the session materials to be developed and rolled out to all departments. With a bank of evaluated activities behind us, from here-on out the focus will be on sustaining delivery levels and working with as many young people and teachers as effectively as possible.

\section{References}

1. Brown, N. (2006) Steering Group on a study of physics departments in six universities in South East England London: Nigel Brown and Associates

2. HEFCE. (2008) Sustaining science and other key vulnerable subjects in higher education. Bristol: HEFCE Available from: <www.hefce.ac.uk/aboutus/sis/SIVS_glossy.pdf> last accessed 10 Jan 2011

3. Council for Science and Technology. (2000). Science Teachers: A report on supporting and developing the profession ofscience teaching in primary and secondary schools. London: Council for Science and Technology.

4. House of Commons Science and Technology Committee. (2002). Science Education from 14 to 19. London: The Stationery Office Limited.

5. Millar, R., \& Osborne, J. (1998). Beyond 2000: Science education for the future. London: King's College London, School of Education.

6. Roberts, G. (2002). SET for success: The supply of people with science, technology, engineering and mathematics skills. London: HM Treasury.

7. Smithers, A., \& Robinson, P. (2007). Physics in schools and universities: Bucking the trend. University of Buckingham, Centre for Education and Employment Research.

8. LightTAG $<$ lighttag.wordpress.com/> last accessed 3 May 2011 